University of Nebraska - Lincoln

DigitalCommons@University of Nebraska - Lincoln

Faculty Publications, Department of Psychology

Psychology, Department of

2010

Emotion Dysregulation and Risky Sexual Behavior in Revictimization

Terri L. Messman-Moore

Miami University - Oxford

Kate L. Walsh

University of Nebraska-Lincoln

David K. DiLillo

University of Nebraska-Lincoln, ddilillo@unl.edu

Follow this and additional works at: https://digitalcommons.unl.edu/psychfacpub

Part of the Psychiatry and Psychology Commons

Messman-Moore, Terri L.; Walsh, Kate L.; and DiLillo, David K., "Emotion Dysregulation and Risky Sexual Behavior in Revictimization" (2010). Faculty Publications, Department of Psychology. 582.

https://digitalcommons.unl.edu/psychfacpub/582

This Article is brought to you for free and open access by the Psychology, Department of at DigitalCommons@University of Nebraska - Lincoln. It has been accepted for inclusion in Faculty Publications, Department of Psychology by an authorized administrator of DigitalCommons@University of Nebraska - Lincoln. 


\title{
Emotion Dysregulation and Risky Sexual Behavior in Revictimization
}

\author{
Terri L. Messman-Moore ${ }^{\mathrm{a},{ }^{*},}$ Kate L. Walsh ${ }^{\mathrm{b}}$, David DiLillo ${ }^{\mathrm{b}}$

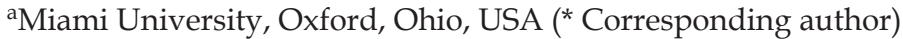 \\ bUniversity of Nebraska-Lincoln, Lincoln, Nebraska, USA
}

Keywords: Revictimization, Child sexual abuse, Child physical abuse, Rape, Emotion dysregulation, Psychosexual behavior

\begin{abstract}
Objective: The current study examined emotion dysregulation as a mechanism underlying risky sexual behavior and sexual revictimization among adult victims of child sexual abuse (CSA) and child physical abuse (CPA).

Methods: Participants were 752 college women. Victimization history, emotion dysregulation, and risky sexual behavior were assessed with anonymous, self-report surveys utilizing a cross-sectional design.

Results: Approximately $6.3 \%$ of participants reported CSA, 25.5\% reported CPA, and $17.8 \%$ reported rape during adolescence or adulthood. CSA and CPA were associated with increased risk for adolescent/adult rape; $29.8 \%$ of CSA victims and $24.3 \%$ of CPA victims were revictimized. Path analytic models tested hypothesized relationships among child abuse, emotion dysregulation, adolescent/adult rape and three forms of risky sexual behavior (e.g., failure to use condoms, contraception, or having sex with someone under the influence of alcohol/drugs), including frequency of risky sexual behavior with a regular dating partner, with a stranger, and lifetime number of intercourse partners. Emotion dysregulation mediated revictimization for both CSA and CPA. Emotion dysregulation also predicted lifetime number of sexual partners and frequency of risky sex with a stranger, but not frequency of risky sex with a regular dating partner. Conclusions: Findings suggest that emotion dysregulation is a distal predictor, and risky sex, particularly with lesser known partners, is a proximal predictor of sexual revictimization. Because emotion dysregulation also maintained a significant direct path to revictimization, risky sexual behavior appears to be one of several proximal risk factors for revictimization.

Practice implications: Findings confirm that emotion dysregulation is a critical pathway to more proximal risk factors such as risky sexual behavior, and suggest that clinical interventions aimed at improving emotion dysregulation may help reduce risky sexual behavior and risk for revictimization.
\end{abstract}

\section{Introduction}

Child sexual abuse (CSA) victims are between 2 and 11 times more likely to be raped in adulthood, with risk increasing exponentially with severity of CSA (Fergusson, Horwood, \& Lynskey, 1997; Wyatt, Gutherie, \& Notgrass, 1992). In a review of the then nascent literature, Messman and Long (1996) noted that few empirical studies were designed to examine the issue of revictimization. Since then, studies designed specifically to examine this phenomenon provide evidence of revictimization among college students (Messman-Moore \& Long, 2000), community women (Kimerling, Alvarez, Pavao, Kaminski, \& Baumrind, 2007), in patients (Cloitre, Tardiff, Marzuk, Leon, \& Portera, 1996), female inmates (Walsh, DiLillo, \& Scalora, in press), and military veterans (Schultz, Bell, Naugle, \& Polusny, 2006). Revictimization also has been documented among ethnically diverse populations, including Latina, African American, and Asian American women (Urquiza \& Goodlin-Jones, 1994), bisexual women and gay men (Heidt, Marx, \& Gold, 2005), and low-income, urban women (Siegel \& Williams, 2003). Revictimization appears to compound the psychological impact of prior victimization, and is associated with increased distress among victims, including higher levels of anxiety, lifetime and current depression, lifetime and current PTSD, dissociation, binge drinking and past month drug use (Casey \& Nurius, 2005; Cloitre, Scarvalone, \& Difede, 1997; Kimerling et al., 2007).

The widespread psychological impact of revictimization raises the critical question of why some CSA survivors experience additional victimizations while others do not. Identifying factors that distinguish these groups will inform interventions designed to prevent revictimization and the psychological burden assciated with it.

Revictimization Models and Prevention

Most models of revictimization focus on how traumatic sequelae associated with CSA influence psychological, cognitive, behavioral, and interpersonal functioning, which subsequently increase risk for revictimization (Cloitre \& Rosenberg, 2006; Marx, Heidt, \& Gold, 2005; Messman-Moore \& Long, 2003). Numerous forms of CSArelated symptomatology or impaired functioning have been linked to revictimization, including posttraumatic symptomatology (Risser, Hetzel-Riggin, Thomsen, \& McCanne, 2006), dissociation (Noll, Horowitz, Bonano, Trickett, \& Putnam, 2003), risk perception (Messman-Moore \& Brown, 2006), alcohol and substance abuse (Casey \& Nurius, 2005), interpersonal difficulties (Rich, Gidycz, Warkentin, Loh, \& Weiland, 2005), and risky sexual behavior (Orcutt, Cooper, \& Garcia, 2005).

Although this work has been useful in identifying factors that may mediate the association between CSA and adult revictimization, this knowledge has not necessarily translated into effective prevention programming. Al- 
though some suggest that programming may be helpful in reducing sexual assault rates, these interventions have shown relatively little effectiveness for women who already have been sexually victimized (Gidycz et al., 2001; Marx, Calhoun, Wilson, \& Meyerson, 2001). A program by Gidycz et al. (2001) reduced revictimization during a 6-month follow-up for women with moderate (as opposed to severe) sexual victimization, and Marx et al. (2001) reduced risk for verbally coercive revictimization (versus rape) in a 2-month follow-up period. No studies of revictimization prevention have focused on addressing traumatic sequelae (e.g., PTSD symptoms, alcohol use) to reduce risk, although in a pilot treatment study of women who were recently sexually victimized, those receiving group therapy were less likely to report sexual revictimization post-treatment (Classen, Koopman, Nevill-Manning, \& Spiegel, 2001). Given the modest success of current interventions, it seems prudent to continue to identify risk factors that could be addressed.

One potential explanation for the limited success in revictimization prevention is the failure to adequately specify pathways leading from early to later victimization. Empirical studies demonstrate that multiple mediating processes underlie revictimization, yet it is not feasible to incorporate all risk factors into revictimization interventions. Moreover, interventions may be more efficient and effective if they incorporate mechanisms that underlie multiple empirically identified mediators of revictimization. Most revictimization risk factors fall within one of three domains: PTSD, interpersonal relatedness difficulties, and affect dysregulation (Cloitre \& Rosenberg, 2006). In fact, the majority of identified risk factors (i.e., dissociation, substance use, risky sexual behavior, risk perception) may be linked to failure to self-regulate negative affective states, which is particularly likely to occur among CSA victims (Cloitre \& Rosenberg, 2006; Marx et al., 2005). If emotion dysregulation leads to behaviors that increase risk for revictimization, then an effective yet parsimonious intervention may be developed focusing on this difficulty. Thus, secondary preventive interventions with high-risk women (i.e., targeting women high in emotion dysregulation) may be a worthwhile strategy. However, although intervention focused on emotion dysregulation makes intuitive sense, it is important to empirically establish its relevance in the process of revictimization. If this can be accomplished, emotion dysregulation would be a promising target for intervention because it appears to precede numerous proximal risk factors, setting the stage for increased vulnerability and revictimization.

Emotion Dysregulation

Childhood maltreatment is known to have a detrimental impact on development of emotion regulation capacity, and deficits in emotion regulation strategies increase vulnerability for psychological disorders. Emotion dysregulation typically begins in childhood (e.g., Shields \& Cicchetti, 1998) and often persists into adolescence and adulthood (Kilpatrick et al., 2003).

Some conceptualizations of emotion regulation emphasize the control of emotional experience and expression (especially of negative emotional states), while others emphasize that adaptive emotion regulation involves awareness and understanding of emotions (Thompson \& Calkins, 1996). Hayes, Wilson, Gifford, Follette, and Strosahl (1996) posit that efforts to avoid (and control) internal experiences, including emotional experience - a phenomenon called experiential avoidance - is inherently harmful to psychological functioning and may underlie many psychological disorders. There is growing consensus that adaptive emotion regulation involves the flexible use of skills to modulate emotional experience (e.g., altering the intensity or duration of an emotion) rather than eliminating certain (negative) emotions. A recent comprehensive model proposed by Gratz and Roemer (2004) integrated numerous aspects of emotion regulation including emotional awareness, understanding and acceptance; ability to control impulsive behaviors when experiencing negative emotions; and ability to use emotion regulation strategies flexibly to modulate emotional responses to meet individual goals and situational demands.

Among child abuse victims, difficulties in emotion regulation often extend beyond childhood. Adult CSA victims exhibit numerous aspects of emotion dysregulation including greater difficulty identifying and regulating emotional states, lower levels of emotional acceptance, and increased experiential avoidance (Batten, Follette, \& Aban, 2001; Gratz, Bornovalova, Delaney-Brumsey, Nick, \& Lejuez, 2007). Adult sexual assault is also associated with heightened experiential avoidance (Boeschen, Koss, Figueredo, \& Coan, 2001) and alexithymia (Zeitlin, McNally, \& Cassiday, 1993). Deficits in any one or more aspects of emotion regulation may result in maladaptive strategies to address negative affect including self-harm, binge eating, substance use, and risky sexual behavior, all of which are problematic. However, risky sexual behavior is especially relevant to the context of revictimization, given extensive evidence linking women's sexual behavior to increased vulnerability for sexual assault.

\section{Risky Sexual Behavior}

Risky sexual behavior is one of the most consistent predictors of revictimization (Messman-Moore \& Long, 2003). CSA is associated with an increased number of sexual partners, higher frequency of intercourse, and younger age at first consensual intercourse (Meston, Heiman, \& Trapnell, 1999; Noll, Trickett, \& Putnam, 2003). 
Furthermore, victims of CSA are more likely to engage in casual sex (i.e., sex outside of a committed relationship; Meston et al., 1999) as well as sex without protection against pregnancy or sexually transmitted diseases (Lemieux \& Byers, 2008; Noll et al., 2003a, 2003b). Women who are revictimized report more consensual sexual activity (Himelein, Vogel, \& Wachowiak, 1994) and casual sex (Lemieux \& Byers, 2008). In several studies, sexual behavior mediated the relationship between CSA and revictimization (Krahé, Scheinberger-Olwig, Waizenhöfer, \& Kolpin, 1999; Orcutt et al., 2005).

Risky sexual behavior has been conceptualized as a tension-reducing behavior utilized to regulate emotional experiences among child abuse victims. Few studies empirically test this assumption, although there is evidence that experiential avoidance predicts risky sexual behavior in CSA victims (Batten et al., 2001). Revictimized women are more likely to "cope" with PTSD via substance use or maladaptive sexual behavior (Filipas \& Ullman, 2006), and having sex to reduce negative affect partially mediated the relation between CSA and revictimization in a prospective study of community women (Orcutt et al., 2005). Although CSA victims appear likely to use sexual behavior as a strategy for emotion regulation, there are no available studies that explicitly examine emotion dysregulation in relation to risky sexual behavior and revictimization. However, studies of factors that motivate sexual activity among community and college populations suggest that having sex to cope with negative affect is not uncommon (Cooper, Shapiro, \& Powers, 1998). Coping sex motives have been linked to a pattern of risky sexual behavior that involved more frequent intercourse outside the context of a stable and exlusive relationship (Cooper et al., 1998). Therefore, the link between revictimization and risky sexual behavior may exist for at least two reasons. First, CSA victims are more likely to experience emotion dysregulation and hence are at increased risk for using sex to cope, and second, using sex to cope predicts potentially problematic sexual behavior that increases risk for sexual assault given its form, frequency, and context.

\section{Child Physical Abuse and Revictimization}

The majority of revictimization research has focused on CSA and adult sexual victimization (Messman-Moore \& Long, 2003). In fact, some researchers argue that CSA is uniquely associated with maladaptive sexual behavior (and thus, sexual revictimization) because of the specific sexual nature of CSA that may shape sexual beliefs and behaviors in developmentally inappropriate ways (Briere \& Runtz, 1990; Meston et al., 1999). However, child physical abuse (CPA) is associated with revictimization in a variety of forms, including domestic violence and adult physical assault, although there is mixed evidence that CPA predicts adult sexual victimization specifically (Cloitre \& Rosenberg, 2006). Nonetheless, CPA has been linked to sexual revictimization in a nationally representative community sample (Desai, Arias, Thompson, \& Basile, 2002), as well as in clinical (Cloitre et al., 1996) and college samples (Schaaf \& McCanne, 1998). Given that emotion dysregulation also is associated with CPA (Teisel \& Cicchetti, 2008), it is reasonable to assume that emotion dysregulation might also explain CPA victims' increased risk for adult sexual victimization.

\section{Study Purpose and Hypotheses}

The purpose of the current study is to determine whether emotion dysregulation is a mechanism underlying the child-adult victimization association, and also whether its presence sets the stage for at least one proximal risk factor for revictimization - risky sexual behavior. Numerous theories posit that emotion dysregulation plays an influential, if not central, role in revictimization (e.g., Cloitre \& Rosenberg, 2006; Marx et al., 2005), and revictimization has been associated with tension-reducing behaviors, most notably risky sexual behavior. However, there are no studies that explicitly examine whether this purported "tension-reducing" behavior is in fact related to emotion dysregulation. Thus, the main purpose of the current study is to assess emotion dysregulation and examine its role in sexual revictimization.

We hypothesize that the relationship between child abuse (sexual and physical) and adult rape will be explained by emotion dysregulation and risky sexual behavior. Specifically, we propose that abuse-related emotion dysregulation will predict risky sexual behavior, which will predict revictimization. Further, a direct path from emotion dysregulation to revictimization is also expected, given that other proximal tension-reducing behaviors (e.g., substance use) predict revictimization.

Method

Participants

Participants were 752 female college students at a mid-sized public university in the Midwest who agreed to participate in exchange for research credit or extra credit for a psychology course. Participants were on average 18.76 years old $(\mathrm{SD}=1.01)$. The majority was unmarried $(92.5 \%)$, Caucasian $(91.5 \%)$, either Protestant or Catholic $(74.7 \%)$, and from upper-middle class backgrounds (47\% reported family annual income greater than $\$ 100,000$ ). 


\section{Measures}

Child abuse. Childhood abuse was assessed with a paper-and-pencil version of the Computer Assisted Maltreatment Inventory (CAMI; DiLillo et al., 2010). Child sexual abuse (CSA) was assessed with a series of screener questions that, if answered affirmatively, were followed by a more detailed set of questions examining the characteristics of the CSA. Those who reported experiencing (before the age of 14) sexual touching, sexual kissing, or oral, anal, or vaginal intercourse with a family member, or a person who was 5 or more years older, were considered victims of CSA. Additionally, persons who reported experiencing any of these activities against their will, regardless of age difference or relationship to the perpetrator, were also classified as CSA victims. Voluntary sexual play with a similar age peer and voluntary sexual activities with a dating partner were not considered CSA.

The child physical abuse (CPA) subscale of the CAMI asks if the respondent was the victim of specific acts of physical violence perpetrated by a parent or adult caregiver before he/she (the participant) was 18. Examples of items include "Did either parent or any other adult caregiver grab or shake you hard?" or "Did either parent or any other adult caregiver threaten you with a weapon such as a gun or a knife?" Participants give yes/no responses to each of these items. Women were identified as CPA victims if they reported that a caregiver inflicted any one of the following acts on the individual before age 18: spanked them to the point of bruising, hit them with a fist, kicked them, threw or knocked them down, choked them, burned them intentionally, threatened them with a weapon, or used a weapon to hurt them.

Multiple studies have examined the psychometric properties of the CAMI within college populations (e.g., DiLillo et al., 2006, 2010). Classification of abuse status on the CAMI shows strong temporal stability (DiLillo et al., 2010) as well as high agreement with the Childhood Trauma Questionnaire (CTQ; Bernstein \& Fink, 1998), a widely used and well validated measures of prior abuse (DiLillo et al., 2006). Further, participants' responses to the CAMI show little to no associations with measures of social desirability (DiLillo et al., 2010).

Emotion dysregulation. Emotion dysregulation was assessed with the Difficulties in Emotion Regulation Scale (Gratz \& Roemer, 2004), a 36-item self-report measure. Participants endorse each statement on a 5-point frequency scale. The DERS includes 6 subscales (clarity, awareness, nonacceptance, ability to engage in goal-directed behavior despite negative emotional states, ability to refrain from impulsive behavior when experiencing negative emotional states and flexible use of emotional regulation strategies) as well as a total score, which was used in the current study; higher scores indicate greater emotion dysregulation. The DERS has high internal consistency, good test-retest reliability, and adequate construct and predictive validity (Gratz \& Roemer, 2004). In the current study, the total score internal consistency alpha was 0.94 .

Risky sexual behavior. A revised version of the Cognitive Appraisal of Risky Events (CARE-R; Katz, Fromme \& D’Amico, 2000) was used to assess frequency of risky sexual behavior over the last 6 months. Participants indicated how often they had engaged in the given activity on a 7-point scale ranging from 0 to 1 time, 2-4 times, 5-9 times, 10-20 times, 21-30 times, and 31 or more times over the past 6 months. In previous studies, risky sexual behavior was examined by summing the frequency responses for all risky sex items into one scale, collapsing across partner type (Katz et al., 2000). In the current study, this scale was divided based upon type of partner. Risky sexual behavior was assessed with two types of partners - a "regular partner" (as defined by the participant) and "someone just met" (a stranger) - and involved the following behaviors: sex with a partner who the respondent had just met or did not know well, sex under the influence of alcohol or drugs, sex without protection against pregnancy, and sex without protection against STD's. Cronbach's alpha for risky sexual behavior with a regular partner was 0.76 , while alpha for risky sexual behavior with a stranger was 0.74 . Number of lifetime sexual partners was assessed with a two-part question: "Have you ever had sexual intercourse (vaginal or anal) when you wanted to (without force)?" followed by "With how many different partners?"

Adolescent/adult rape (revictimization). Adolescent and adult rape was assessed with the Sexual Experiences Survey (SES), a widely used self-report measure (Koss, Gidycz, \& Wisiniewski, 1987; Koss \& Oros, 1982). This measure was modified to assess specific sexual experiences since age 14 in greater detail (e.g., additional questions were added regarding oral-genital contact). Questions regarding alcohol-facilitated victimization were modified according to suggestions by Muehlenhard, Powch, Phelps, and Giusti (1992). Rape was defined as completed, unwanted oral-genital, vaginal, or anal penetration due to the woman's inability to consent or resist due to her level of intoxication (due to alcohol or drugs) or due to threats or use of physical force.

\section{Procedure}

Participants were recruited using an online tool, Experimetrix.com, for a study entitled "College Women's Beliefs about Interpersonal Relationships." After providing informed consent, the women completed anonymous paper-and-pencil surveys in groups of 5-20 participants. Following completion of the survey, participants were 
Table 1 Zero-order correlations among study variables $(N=752)$.

$\begin{array}{lllccccc} & \text { CSA } & \text { CPA } & \text { Adult rape } & \text { DERS total } & \text { \# Sex partners } & \text { Risky Sex-Reg } & \text { Risky Sex-Str } \\ \text { CSA } & 1.0 & 0.16^{* * *} & 0.08^{*} & 0.15^{* * *} & 0.18^{* * *} & 0.14^{* * *} & 0.05^{\text {ns }} \\ \text { CPA } & 1.0 & 0.10^{* *} & 0.20^{* * *} & 0.15^{* * *} & 0.17^{* * *} & 0.08^{*} & \\ \text { Adult rape } & 1.0 & 0.14^{* * *} & 0.31^{* * *} & 0.26^{* * *} & 0.31^{* * *} & & \\ \text { DERS total } & 1.0 & 0.14^{* * *} & 0.07^{\text {ns }} & 0.19^{* * *} & & \\ \text { \# Sex partners } & 1.0 & 0.30^{* * *} & 0.55^{* * *} & & & \\ \text { Risky Sex-Reg } & 1.0 & 0.21^{* * *} & & & & \\ \text { Risky Sex-Str } & 1.0 & & & & & \end{array}$

Note. CSA = Child Sexual Abuse CPA = Child Physical Abuse; DERS = Difficulties in Emotion Regulation Scale; Risky SexReg = frequency of sexual behavior in past 6 months with a "regular" partner; Risky Sex-Str = frequency of sexual behavior with a "stranger" or "someone just met".

$* * * p<0.001$.

$* * p<0.01$.

${ }^{*} p<0.05$.

debriefed and provided contact information for the researchers and counseling services. All study procedures were approved by the primary author's institutional review board.

Results

Victimization Prevalence

CSA, CPA, and adolescent/adult rape were computed as dichotomous variables. Approximately $6.3 \%$ of women $(n=47)$ reported a history of CSA and $25.5 \%(n=192)$ reported a history of CPA. For those respondents reporting CSA, $63.8 \%$ reported abuse by a family member or parental figure, $55.3 \%$ reported abuse involving completed or attempted penetration, $47.8 \%$ reported a duration of abuse of at least 1 year, and $59.6 \%$ reported abuse that occurred due to threats or force. For those respondents reporting CPA $(n=192), 81.8 \%$ reported being spanked so hard that it left a bruise or mark, $61.3 \%$ were hit or spanked with a hard object, $34.6 \%$ were thrown or knocked down, $17.2 \%$ were kicked, and $10.9 \%$ were hit with a fist.

Approximately $17.8 \%(n=134)$ of women reported at least one experience of adolescent or adult rape since age 14 (8 women did not provide complete data on the SES and were omitted from analyses). Chi-square analyses were computed to examine the overlap between each form of child abuse and adolescent/adult rape, to establish the presence of revictimization. The association between CSA and adolescent/adult rape was significant, $X^{2}(1$, $n=744)=4.71, p=0.03$, with $29.8 \%$ of CSA victims reporting adult rape compared to $17.2 \%$ of CSA non-victims. The association between CPA and adolescent/adult rape also was significant, $X^{2}(1, n=744)=6.87, p=0.009$, with $24.3 \%$ of CPA victims reporting adult rape compared to $15.9 \%$ of CPA non-victims. There was also a significant association between the two forms of child abuse, $X^{2}(1, n=752)=20.17, p<0.001 ; 53.2 \%$ of CSA victims also experienced CPA, and $13 \%$ of CPA victims also experienced CSA.

Correlations among Study Variables

Correlations among study variables are listed in Table 1. Higher levels of emotion dysregulation were associated with the presence of CSA, CPA, and with adolescent/adult rape. Emotion dysregulation and risky sexual behavior were also correlated, with greater emotional dysfunction associated with higher frequency of risky sexual behavior with a stranger (but not with a regular dating partner) in the past six months as well as with an increased number of lifetime sexual intercourse partners. Adolescent/adult rape was associated with greater emotional dysfunction and higher levels of risky sexual behavior (frequency of risky sexual behavior with a regular partner, with a stranger, and lifetime number of sexual intercourse partners).

\section{Path Modeling}

Three proposed models were evaluated. For each model, we hypothesized that child abuse would predict emotional dysregulation, which would predict risky sexual behavior, which would predict adolescent/adult rape. Three models were examined, one for each form of risky sexual behavior: frequency of risky behavior with a dating partner, frequency of risky behavior with a stranger, and lifetime number of sexual intercourse partners. In all models, we also predicted a significant direct path from emotion dysregulation to rape, acknowledging the likely presence of other dysregulated behaviors (e.g., substance use) that may also lead to revictimization. 


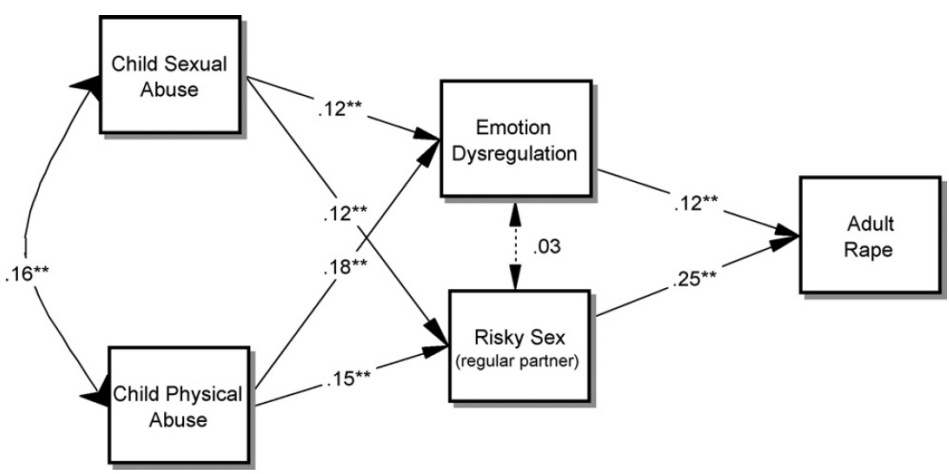

Figure 1. Model examining emotion dysregulation and risky sex with a regular partner as correlated intervening variables in the association between maltreatent and rape.

To evaluate the proposed models, path analysis was employed using M plus, version 5.0. Where appropriate, good model fit was evaluated using Kline's (2005) recommendation that the model chi-square statistic be nonsignificant and Hu and Bentler's (1999) recommendations that the Comparative Fit Index (CFI) be greater than 0.95, the Root Mean Square Error of Approximation (RMSEA) be less than or equal to 0.06, and the Standardized Root Mean Square Residual (SRMR) be less than 0.08. In all models, rape was an endogenous variable while CSA and CPA were exogenous variables. Effect size measures (e.g., $R^{2}$ ) also will be presented to facilitate an examination of the ratio of variance explained in the model to the total variance in the model (Cohen, 1988). Prior to testing models involving emotion dysregulation and risky sexual behavior, a simple regression model predicting rape from CSA and CPA with a correlation specified between CSA and CPA was examined. When examined simultaneously, CPA $(\beta=0.09, p<0.05)$, but not CSA $(\beta=0.07$, ns), was significantly positively associated with rape. Further, there was a significant positive association between CSA and CPA, $r=0.16, p<0.05$.

All subsequent path models built on this basic regression by examining emotion dysregulation and various forms of risky sexual behavior (e.g., risky sex with a regular dating partner or with a stranger during the last six months as well as the total number of lifetime sexual partners) as intervening variables in the association between child maltreatment (CSA and CPA) and rape. First, a sequential model predicting that CSA and CPA would lead to emotion dysregulation, which would lead to risky sex with a regular dating partner during the last 6 months, which, in turn, would lead to rape, was examined. A correlation was specified between CSA and $\mathrm{CPA}$, and all endogenous variables were regressed on the preceding variables in the model, resulting in a saturated model from which fit statistics could not be obtained. However, associations between child maltreatment (CSA and CPA) and rape were not significant. Further, a significant association between emotion dysregulation and risky sex with a regular dating partner was not observed in this model. To evaluate model fit, the paths between both forms of maltreatment and rape were removed, and a correlation between emotion dysregulation and risky sex with a regular dating partner was specified (as opposed to a causal path). This revised model was a good fit for these data, $X^{2}(3)=1.7, p=0.60$, RMSEA $=0.00$; SRMR $=0.01$; CFI $=1.0$, as indicated by a non-significant chi-square value and other excellent fit statistic estimates. The model $\left(R^{2}\right)$ accounted for $8 \%$ of the variance in rape and all path coefficients were in the hypothesized direction. Standardized path coefficients for this model are presented in Figure 1.

Next, a saturated sequential model predicting that CSA and CPA would lead to emotion dysregulation, which would predict risky sex with a stranger in the last 6 months, which, in turn, would lead to rape, was examined. Again, the paths between child maltreatment (both CSA and CPA) and rape were not significant. To evaluate model fit, these two non-significant paths were removed. The resulting model was an excellent fit for these data, $X^{2}(4)=5.8, p=0.21$, RMSEA $=0.03$; SRMR $=0.02$; CFI $=0.99$. Interestingly, however, CSA and CPA were not associated with risky sex with a stranger in the overall model. Other path coefficients were significant and in the hypothesized direction. The model accounted for $10 \%$ of the variance in rape. Standardized path coefficients for this model are presented in Figure 2.

Finally, a saturated sequential model predicting that CSA and CPA would lead to emotion dysregulation, which would predict lifetime number of sexual partners, which, in turn, would predict rape, was examined. Because the paths between child maltreatment (both CSA and CPA) and rape again were not significant, these paths were excluded from the final model.

The resulting model was an excellent fit for these data, $X^{2}(2)=1.13, p=0.57$; RMSEA $=0.00 ;$ SRMR $=0.01$; CFI 


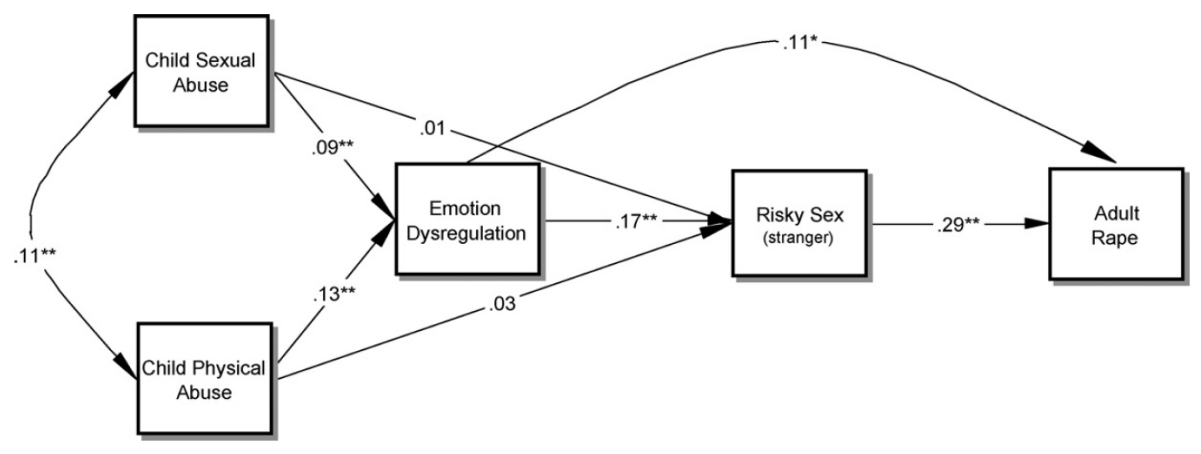

Figure 2. Sequential model examining emotion dysregulation and risky sex with a stranger as pathways through which maltreatment leads to rape.

$=1.0$; all paths in the model were significant and in the hypothesized direction. The model accounted for $10 \%$ of the variance in rape. Standardized path coefficients for this model are presented in Figure 3.

\section{Discussion}

This is the first study to find empirical support for theoretical models (Cloitre \& Rosenberg, 2006; Marx et al., 2005) claiming that emotion dysregulation influences risky behavior and increases vulnerability for revictimization. As hypothesized, Emotion dysregulation had an indirect effect on revictimization via its impact on risky sex, but also retained a significant direct effect on revictimization. Although it is not known in the current study whether women with poor emotion regulation skills were motivated to engage in risky sex to cope with negative affect, these results are similar to those of Orcutt et al. (2005) who found that sex to reduce negative affect mediated the link between CSA and adult rape. However, our results also indicate that other revictimization risk factors associated with emotion dysregulation (i.e., alcohol use) should be studied, given the significant direct relationship between emotion dysregulation and revictimization in all models. Together these findings suggest that emotion dysregulation is a critical mechanism to address, and that doing so may reduce rates of risky sexual behavior and subsequent revictimization.

Consistent with previous studies (Himelein et al., 1994; Lemieux \& Byers, 2008), the current study indicates that risky sexual behavior is a significant risk factor for revictimization. Number of lifetime sexual intercourse partners was the strongest predictor of adolescent/adult rape, although frequency of risky sex with a stranger and with a regular dating partner also predicted revictimization. Interestingly, emotion dysregulation was linked only to number of sexual partners and risky sexual behavior with a stranger, yet child maltreatment (CSA and CPA) was only associated with risky sexual behavior with a regular dating partner. Similar to Batten et al. (2001), the current study did not find a link between emotion dysregulation and risky sexual behavior with a regular (established) partner. Findings suggest that women with poor emotion regulation skills may engage in risky sexual behavior, particularly with lesser known partners, in efforts to manage negative affect, and that child maltreatment is indi-

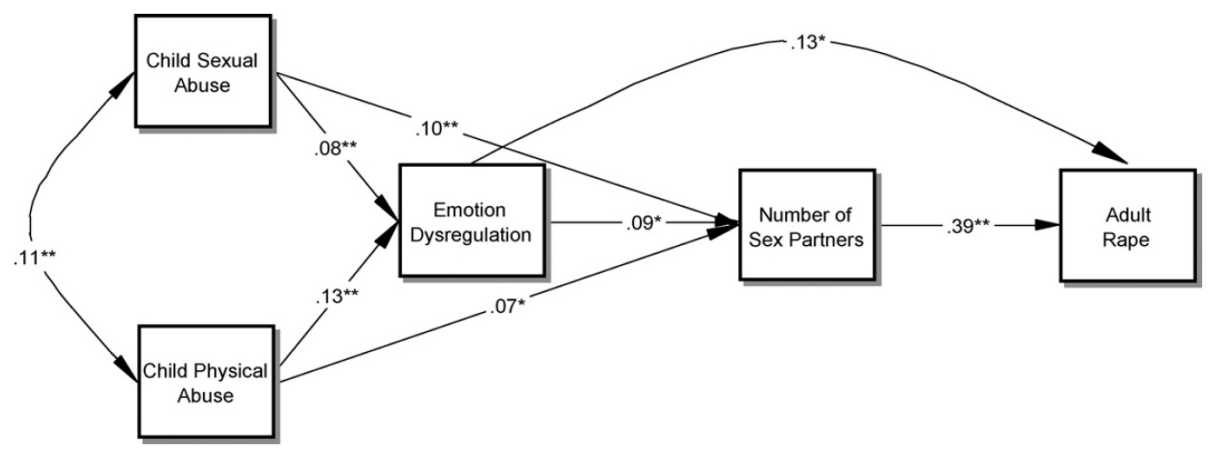

Figure 3. Sequential model examining emotion dysregulation and lifetime number of sexual partners as pathways through which maltreatment leads to rape. 
rectly linked with risky sex with a stranger via emotion dysregulation. Other mechanisms within the interpersonal domain may better explain the association between risky sexual behavior and revictimization within an ongoing intimate relationship, including interpersonal schemas (DePrince, Combs, \& Shanahan, 2009), interpersonal functioning (Rich et al., 2005), or impaired assertiveness (Testa, Van Zile-Tamsen \& Livingston, 2007).

Although risky sexual behavior with a regular partner did predict revictimization, such behavior within a relationship may more often lead to other negative outcomes (e.g., unintended pregnancies, STIs, or lowered self-esteem), especially given that risky sexual behavior is a stronger predictor of sexual victimization by non-intimate (versus intimate) perpetrators (Testa et al., 2007). Findings support continued examination of numerous facets of sexual behavior as predictors of revictimization, including frequency of sexual behavior. Future studies should also consider in more depth the context of sexual activity (i.e., sexual behavior while intoxicated), the nature of the relationship with the perpetrator (e.g., casual versus relationship partners) and perpetrator characteristics (e.g., attitudes towards women, acceptance of sexual aggression).

Both child sexual and physical abuse were associated with emotion dysregulation, as well as directly linked to risky sexual behavior with a regular partner. Other studies have supported a link between CPA and risky sexual behavior. For example, Wilson and Widom (2008) found that in addition to CSA, CPA and childhood neglect predicted earlier onset of sexual activity and greater likelihood of prostitution. Moreover, Lemieux and Byers (2008) found that victims of CPA as well as victims of CSA were more likely than nonvictims to have casual sex and unprotected sex. However, in at least one study, CPA was associated with more sexual behavior that is associated with HIV risk, whereas CSA was only associated with risky sexual behavior when it occurred with other forms of abuse (Cunningham, Stiffman, Dore, \& Earls, 1994).

Both forms of child abuse were associated with adolescent/adult rape, although when examined together, the association between CSA and revictimization was no longer significant. It should be noted, however, that the relative strength of the relationships between both forms of early abuse and later revictimization were relatively similar in magnitude (0.07 vs. 0.09).

These findings, along with the significant overlap between CSA and CPA in the present study, are consistent with earlier studies suggesting that CSA is linked to revictimization only in the context of CPA (Cloitre et al., 1996; Schaaf \& McCanne, 1998), or that the risk for revictimization is greater if CSA victims experience CPA as well (Smith, Davis, \& Fricker-Elhai, 2004). Overall, results suggest continued examination of sexual and physical abuse, particularly in the context of emotion dysregulation, as risk factors for revictimization.

This is the first study to specifically assess emotion dysregulation and to examine its impact on revictimization, yet its findings must be considered in the context of some limitations. The patterns that emerged here should be examined in community and clinical samples to determine the generalizability of these findings, given that college women are likely to function better and have lower levels of overall emotion dysregulation when compared to non-college students. Yet, sexual assault and revictimization remain a significant concern for college women and should remain a focus of our research efforts. Generalizability is further limited by the predominantly Caucasian and upper-middle class sample; thus additional studies are needed to determine whether emotion dysregulation is also a mechanism for revictimization among more ethnically and economically diverse samples. Furthermore, although our results are consistent with the possibility that emotion dysregulation stemming from prior abuse sets the stage for revictimization, the retrospective cross-sectional design prevents conclusions regarding causality and the temporal order of variables. Given that many variables examined could be revictimization outcomes, additional prospective studies are necessary to determine the predictive utility of emotion dysregulation. Finally, although the models examined here fit these data well, the variance accounted for in rape was equivalent to a small effect size (i.e., 0.10). This finding suggests that a great deal of unexplained variance remains and should be the focus of future studies.

Despite these limitations, the present study is a significant first step in establishing the relevance of emotion dysregulation in predicting high risk behaviors that impact sexual revictimization. Future studies should examine other revictimization risk factors associated with emotion dysregulation, including dissociation (Cloitre et al., 1997), risk perception (Messman-Moore \& Brown, 2006), and alcohol and drug use (Ullman \& Najdowski, 2009), to determine whether emotion dysregulation is the underlying mechanism in those relations as well. Furthermore, additional studies are needed to examine revictimization in relation to numerous constructs associated with emotion dysregulation, including alexithymia and experiential avoidance.

We do not yet know whether revictimization is associated with global deficits in emotion dysregulation, or whether specific domains of emotion dysregulation such as emotional nonacceptance, lack of emotional clarity, or a failure to generate or implement effective emotion regulation strategies, are more central in this process. Furthermore, at least two studies (Tull \& Roemer, 2007; Weinberg \& Klonsky, 2009) have raised concerns about the awareness sub- 
scale of the DERS, noting that its lower internal consistency and associations with the DERS total scale (used here) raise questions about its connection to the larger construct of emotion dysregulation. Given these issues, continued study of the DERS is needed and alternate conceptualizations of emotion regulation, including antecedent-focused strategies such as cognitive reappraisal and the response-focused strategy of suppression (Gross \& John, 2003) also should be examined. Finally, the assessment of emotion dysregulation via self-report questionnaires may reveal a limited understanding of this problem, given that acknowledgement of such difficulties on a face-valid measure involves, to some degree, an ability to reflect on one's emotional experience that inherently involves some level of emotional awareness and clarity. Future studies of revictimization should consider mixed methods approaches to assess multiple aspects of emotion dysregulation with experimental methodologies or implicit paradigms.

Although our understanding of the construct of emotion dysregulation continues to evolve, the present study provides important preliminary findings suggesting that the impact of emotion dysregulation on revictimization is deserving of further study. Numerous theories posit that emotion dysregulation plays an influential, if not central, role in revictimization. The present findings confirm that emotion dysregulation is a critical pathway to more proximal risk factors. The door is now open to reonceptualize revictimization interventions in order to more efficiently and therapeutically target emotion dysregulation and reduce risky behavior.

\section{References}

Batten, S.V., Follette, V.M., \& Aban, I. (2001). Experiential avoidance and high-risk sexual behaviors in survivors of child sexual abuse. Journal of Child Sexual Abuse 10: 101-120.

Bernstein, D.P., \& Fink, L. (1998). Childhood Trauma Questionnaire Manual. San Antonio, Tex.: Psychological Corporation.

Boeschen, L.E., Koss, M.P., Figueredo, A.J., \& Coan, J.A. (2001). Experiential avoidance and posttraumatic stress disorder: a cognitive mediational model of rape recovery. Journal of Aggression Maltreatment, and Trauma 4: 211-245.

Briere, J., \& Runtz, M. (1990). Differential adult symptomatology associated with three types of child abuse histories. Child Abuse \& Neglect 14: 357-364.

Casey, E.A., \& Nurius, P.S. (2005). Trauma exposure and sexual revictimization risk: comparisons across single, multiple incident, and multiple perpetrator victimizations. Violence against Women 11: 505-530.

Classen, C., Koopman, C., Nevill-Manning, K., \& Spiegel, D. (2001). A preliminary report comparing trauma-focused and present-focused group therapy against a wait-list condition among childhood sexual abuse survivors with PTSD. Journal of Aggression, Maltreatment, and Trauma 4: 265-288.

Cloitre, M., \& Rosenberg, A. (2006). Sexual revictimization: risk factors and prevention. In: V.M. Follette, \& J.I. Ruzek (Eds.), Cognitive-Behavioral Therapies for Trauma (pp. 321-361). New York: Guilford Press.

Cloitre, M., Scarvalone, P., \& Difede, J. (1997). Posttraumatic stress disorder, self- and interpersonal dysfunction among sexually retraumatized women. Journal of Traumatic Stress 10: 437-452.

Cloitre, M., Tardiff, K., Marzuk, P.M., Leon, A.C., \& Portera, L. (1996). Childhood abuse and subsequent sexual assault among female inpatients. Journal of Traumatic Stress 9(3): 473-482.

Cohen, J. (1988). Statistical Power Analysis for the Behavioral Sciences. Hillsdale, N.J.: Erlbaum.

Cooper, M.L., Shapiro, C.M., \& Powers, A.M. (1998). Motivations for sex and risky sexual behavior among adolescents and young adults: a functional perspective. Journal of Personality and Social Psychology 75: 1,528-1,558.

Cunningham, R.M., Stiffman, A.R., Dore, P., \& Earls, F. (1994). The association of physical and sexual abuse with HIV risk behaviors in adolescence and young adulthood: implications for public health. Child Abuse \& Neglect 18: 233-245.

DePrince, A.P., Combs, M.D., \& Shanahan, M. (2009). Automatic relationship-harm associations and interpersonal trauma involving close others. Psychology of Women Quarterly 33: 163-171.

Desai, S., Arias, I., Thompson, M.P., \& Basile, K.C. (2002). Childhood victimization and subsequent adult revictimization assessed in a nationally representative sample of women and men. Violence and Victims 17: 639-653.

DiLillo, D., Fortier, M.A., Hayes, S.A., Trask, E., Perry, A.R., Messman-Moore, T.L., Fauchier, A., \& Nash, C. (2006). Retrospective assessment of childhood sexual and physical abuse: a comparison of scaled and behaviorally specific approaches. Assessment 13: 297-312.

DiLillo, D., Hayes, S., Fortier, M.A., Perry, A.R., Evans, S., Messman-Moore, T.L., Walsh, K., Nash, C., \& Fauchier, A. (2010). Development and initial psychometric properties of the Computer Assisted Maltreatment Inventory (CAMI): a comprehensive self-report measure of child maltreatment history. Child Abuse and Neglect 34: 305-317.

Fergusson, D.M., Horwood, L.J., \& Lynskey, M.T. (1997). Childhood sexual abuse, adolescent sexual behaviors and sexual revictimization. Child Abuse \& Neglect 21: 789-802.

Filipas, H.H., \& Ullman, S.E. (2006). Child sexual abuse, coping responses, self-blame, post traumatic stress disorder, and adult sexual revictimization. Journal of Interpersonal Violence 21: 652-672.

Gidycz, C.A., Lynn, S.J., Rich, C.L., Marioni, N.L., Loh, C., Blackwell, L.M., Stafford, J., Fite, R., \& Pashdag, J. (2001). The evaluation of a sexual assault risk reduction program: a multisite investigation. Journal of Consulting and Clinical Psychology 69: 1,073-1,078.

Gratz, K.L., Bornovalova, M.A., Delany-Brumsey, A., Nick, B., \& Lejuez, C.W. (2007). A laboratory-based study of the relationship between childhood abuse and experiential avoidance among inner-city substance users: the role of emotional non-acceptance. Behavior Therapy 38: 256-268.

Gratz, K.L., \& Roemer, L. (2004). Multidimensional assessment of emotion regulation and dysregulation: development, factor structure, and initial validation of the Difficulties in Emotion Regulation Scale. Journal of Psychopathology and Behavioral Assessment 26: 41-54.

Gross, J.J, \& John, O.P. (2003). Individual differences in two emotion regulation processes: implications for affect, relationships, and well-being. Journal of Personality and Social Psychology 85: 348-362.

Hayes, S.C., Wilson, K.G., Gifford, E.V., Follette, V.M., \& Strosahl, K. (1996). Experiential avoidance and behavioral disorders: a functional dimensional approach to diagnosis and treatment. Journal of Consulting and Clinical Psychology 64: 1,152-1,168.

Heidt, J.M., Marx, B.P., \& Gold, S.D. (2005). Sexual revictimization among sexual minorities: a preliminary study. Journal of Traumatic Stress 18: 533-540.

Himelein, M.J., Vogel, R.E., \& Wachowiak, D.G. (1994). Nonconsensual sexual experiences in precollege women: prevalence and risk factors. Journal of Counseling \& Development 72: 411-415. 
Hu, L.T., \& Bentler, P.M. (1999). Cut off criteria for fit indices in covariance structure analysis: conventional criteria versus new alternatives. Structural Equation Modeling 6: 1-55.

Katz, E.C., Fromme, K., \& D’ Amico, E.J. (2000). Effects of outcome expectancies and personality on young adults' illicit drug use, heavy drinking, and risky sexual behavior. Cognitive Therapy and Research 24: 1-22.

Kilpatrick, D.G., Ruggiero, K.J., Acierno, R., Saunders, B.E., Resnick, H.S., \& Best, C.L. (2003). Violence and risk of PTSD, major depression, substance abuse/dependence, and comorbidity: results from the national survey of adolescents. Journal of Consulting and Clinical Psychology 71: 692-700.

Kimerling, R., Alvarez, J., Pavao, J., Kaminski, A., \& Baumrind, N. (2007). Epidemiology and consequences of women's revictimization. Women's Health Issues 17: 101-106.

Kline, R.B. (2005). Principles and Practice of Structural Equation Modeling (2 ${ }^{\text {nd }}$ ed.). New York: Guilford Press.

Koss, M.P., Gidycz, C.A., \& Wisiniewski, N. (1987). The scope of rape: incidence and prevalence of sexual aggression and victimization in a national sample of higher education students. Journal of Consulting and Clinical Psychology 55: 162-170.

Koss, M.P., \& Oros, J. (1982). Sexual experiences survey: a research instrument investigating sexual aggression and victimization. Journal of Consulting and Clinical Psychology 50(3): 455-457.

Krahé, B., Scheinberger-Olwig, R., Waizenhöfer, E., \& Kolpin, S. (1999). Childhood sexual abuse and revictimization in adolescence. Child Abuse $\mathcal{E}$ Neglect 23: 383-394.

Lemieux, S.R., \& Byers, E.S. (2008). The sexual well-being of women who have experienced child sexual abuse. Psychology of Women Quarterly 32: $126-144$.

Marx, B.P., Calhoun, K.S., Wilson, A.E., \& Meyerson, L.A. (2001). Sexual revictimization prevention: an outcome evaluation. Journal of Consulting and Clinical Psychology 69: 25-32.

Marx, B.P., Heidt, J.M., \& Gold, S.D. (2005). Perceived uncontrollability and unpredictability, self-regulation, and sexual revictimization. Review of General Psychology 9: 67-90.

Messman,T.L.,\&Long,P.J.(1996).Childsexualabuseanditsrelationshiptorevictimizationinadultwomen:areview.ClinicalPsychologyReview,16,397-420.

Messman-Moore, T.L., \& Brown, A.L. (2006). Risk perception, rape and sexual revictimization: a prospective study of college women. Psychology of Women Quarterly 30: 159-172.

Messman-Moore, T.L., \& Long, P.J. (2003). The role of childhood sexual abuse sequelae in sexual revictimization: an empirical review and theoretical reformulation. Clinical Psychology Review 23(4): 537-571.

Messman-Moore, T.L., \& Long, P.J. (2000). Child sexual abuse and revictimization in the form of adult sexual abuse, adult physical abuse and adult psychological maltreatment. Journal of Interpersonal Violence 15(5): 489-502.

Meston, C.M., Heiman, J.R., \& Trapnell, P.D. (1999). The relation between early abuse and adult sexuality. Journal of Sex Research 36: 385-395.

Muehlenhard, C.L., Powch, I.G., Phelps, J.L., \& Giusti, L.M. (1992). Definitions of rape: scientific and political implications. Journal of Social Issues $48(1): 23-44$.

Noll, J.G., Horowitz, L.A., Bonanno, G.A., Trickett, P.K., \& Putnam, F.W. (2003). Revictimization and self-harm in females who experienced childhood sexual abuse: results from a prospective study. Journal of Interpersonal Violence 18: 1,452-1,471.

Noll, J.G., Trickett, P.K., \& Putnam, F.W. (2003). A prospective investigation of the impact of childhood sexual abuse on the development of sexuality. Journal of Consulting and Clinical Psychology 71: 575-586.

Orcutt, H.K., Cooper, M.L., \& Garcia, M. (2005). Use of sexual intercourse to reduce negative affect as a prospective mediator of sexual revictimization. Journal of Traumatic Stress 18: 729-739.

Rich, C.L., Gidycz, C.A., Warkentin, J.B., Loh, C., \& Weiland, P. (2005). Child and adolescent abuse and subsequent victimization: a prospective study. Child Abuse \& Neglect 29: 1,373-1,394.

Risser, H.J., Hetzel-Riggin, M.D., Thomsen, C.J., \& McCanne, T.R. (2006). PTSD as a mediator of sexual revictimization: the role of reexperiencing, avoidance, and arousal symptoms. Journal of Traumatic Stress 19: 687-698.

Schaaf, K.K., \& McCanne, T.R. (1998). Relationship of childhood sexual, physical and combined sexual and physical abuse to adult victimization and posttraumatic stress disorder. Child Abuse \& Neglect 22(11): 1,119-1,133.

Schultz, J.R, Bell, K.M., Naugle, A.E., \& Polusny, M.A. (2006). Child sexual abuse and adulthood sexual assault among military veteran and civilian women. Military Medicine 171: 723-728.

Shields, A.M., \& Cicchetti, D. (1998). Reactive aggression among maltreated children: the contributions of attention and emotion dysregulation. Journal of Clinical Child Psychology 27: 381-395.

Siegel, J.A., \&Williams, L.M. (2003). Risk factors for sexual victimization of women: results from a prospective study. Violenceagainst Women 9: 902-930.

Smith, D.W., Davis, J.L., \& Fricker-Elhai, A.E. (2004). How does trauma beget trauma? Cognitions about risk in women with abuse histories. Child Maltreatment 9(3): 292-303.

Teisel, M., \& Cicchetti, D. (2008). Physical abuse, cognitive and emotional processes, and aggressive/disruptive behavior problems. Social Development 17: 1-23.

Testa, M., Van Zile-Tamsen, C., \& Livingston, J.A. (2007). Prospective prediction of women's sexual victimization by intimate and nonintimate male perpetrators. Journal of Consulting and Clinical Psychology 75: 52-60.

Thompson, R.A., \& Calkins, S.D. (1996). The double-edged sword: emotion regulation for children at risk. Development and Psychopathology 8: 163-182.

Tull, M.T., \& Roemer, L. (2007). Emotion regulation difficulties associated with the experience of uncued panic attacks: evidence of experiential avoidance, emotional nonacceptance, and decreased emotional clarity. Behavior Therapy 38: 378-391.

Ullman, S.E., \& Najdowski, C.J. (2009). Revictimization as a moderator of psychosocial risk factors for problem drinking in female sexual assault survivors. Journal of Studies on Alcohol and Drugs 70: 41-49.

Urquiza, A.J., \& Goodlin-Jones, B.L. (1994). Child sexual abuse and adult revictimization with women of color. Violence and Victims 9: 223-232.

Walsh, K., DiLillo, D., \& Scalora, M. (in press). The cumulative impact of sexual revictimization on emotion regulation difficulties: an examination of female inmates. Violence against Women.

Weinberg, A., \& Klonsky, E.D. (2009). Measurement of emotion dysregulation in adolescents. Psychological Assessment 21: 616-621.

Wilson, H.W., \& Widom, S. (2008). An examination of risky sexual behavior and HIV in victims of child abuse and neglect: a 30-year follow-up. Health Psychology 27: 149-158.

Wyatt, G.E., Gutherie, D., \& Notgrass, C.M. (1992). Differential effects of women's child sexual abuse and subsequent sexual revictimization. Journal of Consulting and Clinical Psychology 60: 167-173.

Zeitlin, S.B., McNally, R.J., \& Cassiday, K.L. (1993). Alexithymia in victims of sexual assault: an effect of repeated traumatization. American Journal of Psychiatry 150: 661-663. 